\title{
MERITOCRACIA DO SUJEITO: prêmios em Jornalismo pautados pela cidadania como flexibilização da objetividade jornalística
}

MERITOCRACY SUBJECT: Journalism awards in citizenship as guided by the easing of journalistic objectivity

Resumo: a anulação do sujeito (isenção, impessoalidade e imparcialidade) é uma das marcas da adoção dos critérios de Objetividade. Os modelos de Jornalismo Informativo e Jornalismo Investigativo prescrevem esses valores no Brasil já há cinco décadas. O Prêmio Esso, como cultura meritocrática premiativa, foi um dos principais elementos a consolidar a Objetividade como valor inerente ao profissionalismo (Soloski) e à cultura profissional jornalística (Schudson) por validar um protocolo do que é (ou não) a prática e o saber exemplar do jornalismo. Com a ascensão do Terceiro Setor, a partir dos anos 90, no contexto neoliberal, novos atores sociais e modelos surgiram, como o Jornalismo Público. O artigo trata de um novo rol de premiações que flexibiliza a anulação do sujeito da Objetividade propondo um novo padrão de jornalista: um sujeito atuante na realidade social, além da personificação das premiações que não certificam as matérias jornalísticas somente, mas também profissionais e empresas jornalísticas.

Palavras-chave: Jornalista; Meritocracia; Prêmios; Newsmaking.

\begin{abstract}
: the annulment of the subject (exemption, impersonality and impartiality ) is one of the hallmarks of the adoption of the criteria for Objectivity. Models of Journalism and Investigative Journalism News prescribe these values in Brazil for five decades. The Esso Prize, as premiativa meritocratic culture was a key element to strengthen objectivity and professionalism inherent value (Soloski) and professional journalistic culture (Schudson) to validate a protocol of what is (or not) the practice and to know exemplary journalism. With the rise of the Third Sector, from the $90 \mathrm{~s}$, in the neoliberal context, new social actors and models have emerged, such as Public

1 Doutor em Comunicação, formado pelo Programa de Pós-Graduação da Faculdade de Comunicação (PPGFAC) da Universidade de Brasília (UnB) a partir do vínculo com os seguintes projetos de pesquisa credenciados no CNPQ: A ideia do pós-Jornalismo (2010-2013), O Jornalismo como Teoria Democrática (2006-2010) e Como o Terceiro Setor pauta a mídia (2003-2006). Email: rbsn.dias@gmail.com.
\end{abstract}




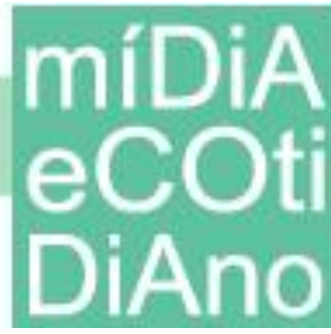

Journalism. The article deals with a new list of awards that eases the annulment of the subject of Objectivity proposing a new standard of journalism: an active subject in social reality, beyond the personification of the awards not only certify the news stories, but also professionals and media companies.

Keywords: Journalist; Meritocracy; Prizes; Newsmaking .

\section{Introdução}

"Pesquisar o Jornalismo Público realizado no Brasil é como procurar por alguém que desconhece o próprio nome”, desabafou Moraes (2011, p. 6). Que dirá, pesquisar os prêmios referentes a esta modalidade de Jornalismo, que são orbitais e carentes de registros históricos e investigação. O artigo trata do modelo de Jornalismo Público que flexibiliza a anulação do sujeito (isenção, imparcialidade, impessoalidade, cão de guarda na democracia participativa) e promove um jornalista ativo socialmente e defensor da cidadania (intervindo na realidade, instrumento de cidadania na democracia participativa).

$\mathrm{O}$ arranjo fundamental para construção deste tema de meritocracia do sujeito está na edição de prêmios com o intuito de criar um sistema de recompensas e validação da conduta exemplar em jornalismo a partir do sujeito atuante no meio social, diferentemente da anulação do sujeito. O Jornalismo Público evoca uma participação mais ativa do jornalista na democracia. Trata-se de um modelo estrangeiro (Civic Journalism), que foi recentemente recepcionado no arcabouço teórico da Comunicação com a substituição de "cívico" por "público". E foi adaptado à realidade brasileira com algumas diferenças da sua concepção original, principalmente por, nos EUA, ter nascido como movimento; e, no Brasil, ter se instalado como uma práxis e um gênero jornalístico.

\section{Jornalismo Público como efeito da crise na Objetividade}

O termo Civic Journalism nasce nos EUA, no fim dos anos 1980, como efeito da frustração com a cobertura sobre a eleição presidencial norte-americana (no ano de 


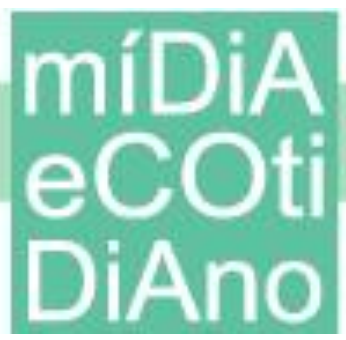

1988, entre o republicano George H. Bush e o democrata Michael Dukakis) ${ }^{2}$. Fruto de uma visão do Jornalismo Informativo, baseado em denúncias, investigações, polêmicas e controvérsias, havia uma queixa sobre as pautas com abordagens negativas das campanhas, apenas enfatizando os embates entre candidatos e partidos. Notou-se que o foco da cobertura não era, de fato, as ideias e nem mesmo questões importantes para a população: itens de cidadania ${ }^{3}$. Talvez um cenário já adiantado por Joseph Pulitzer, jornalista que dá nome ao prêmio mais tradicional em Jornalismo dos EUA, além de ser o fundador do primeiro curso acadêmico na área: “com o tempo, uma imprensa cínica, mercenária, demagógica e corrupta formará um público tão vil como ela mesma"4.

A credibilidade da imprensa teve uma queda, nos EUA, daquele período. Traquina (2001) revela que uma sondagem sobre o nível de confiança do público norteamericano em relação à imprensa chegou a cair de 23\%, em 1973, para 14\%, em 1983, e apenas 10\% em 1994, baseado na premissa de se ter "muita" confiança nos meios de comunicação.

Neste cenário de descrédito Jay Rosen elenca os elementos que propiciaram o surgimento do Civic Journalism, nos anos 90, nos EUA, em meio a essa crise no campo do Jornalismo. Este novo modelo trabalhava com a seguinte premissa: a aproximação entre jornalistas e cidadãos seria fortalecida por meio de uma mudança na forma de produzir notícias e alterações nos fazeres jornalísticos (MORAES, 2011, p. 16).

Tal convicção vem de uma mudança de valor incutida na relação, não entre jornalista e público leitor (consumo), mas entre jornalista e cidadão (cidadania). Essa mudança de eixo tem respaldo no que Teijeiro (2000) indica como uma mudança de cunho filosófico nas relações entre jornalistas e cidadãos, por supor, também, que os

\footnotetext{
2 Tido como "espetáculo perturbador" (Rosen, 1999, p. 39)

${ }^{3}$ Um estudo chamado Pew Center for Civic Journalism (2002), apontava realmente as eleições como item motivador do repensar do Jornalismo na democracia e a proposição do Civic Journalism. Já o relatório intitulado Measuring Civic Journalism Progress: a report across a decade of activity analisou 651 publicações, entre 1994 e 2002, e detectou a adoção dos preceitos desta modalidade jornalística nas coberturas. (MORAES, 2011, p. 14)

${ }^{4}$ Verbo solto: Como diz Nassif, como já dizia Pulitzer... Por Luiz Weis em 24/05/2011. ISSN 1519-7670

- Ano 17 - no 734. Acesso em 20/02/2013

Disponível em http://www.observatoriodaimprensa.com.br/como-diz-nassif-como-ja-dizia-pulitzer
} 


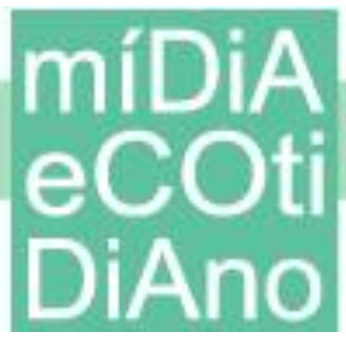

jornalistas devem agir no seio da sociedade como membros responsáveis e devem ser ativos na vida pública.

A gênese do Jornalismo Público se parece com a da hipótese de Agenda Setting (Maxwell McCombs e Shaw, 1972). Ambos nasceram em relação a observações feitas sobre coberturas de períodos eleitorais: sendo um como movimento e o outro como investigação científica. O Jornalismo Público não é uma teoria e nem nasceu como um modelo propriamente dito, mas surgiu como uma ideia dos jornalistas nas eleições presidenciais de 1988, frente à frustração com o noticiário. E se tornou um movimento. Já, os teóricos e autores da hipótese de Agenda Setting estudavam as eleições da cidade de Chapel Hill, no estado da Carolina do Norte (EUA), em 1968.

O Jornalismo Público não é uma nova modalidade de Jornalismo, a rigor, como técnica, divisão do trabalho, profissionalismo, narrativa, formas textuais, identidade, ideologia e representação $\operatorname{social}^{5}$ como foi o caso do Jornalismo Informativo, com a questão da Objetividade ${ }^{6}$. Neste período, tratava-se apenas de um movimento preocupado com a participação mais fundamentada e efetiva do jornalista no Espaço Público estreitamente conectado com os interesses do cidadão.

O Jornalismo Público se tornou uma ideia, mais próxima de um modelo filosofal, do que técnico, com a edição de um livro do jornalista Davis Merrit, tido como um dos fundadores do movimento (chegou inclusive, a publicar um texto com Maxwell McCombs, da hipótese de Agenda Setting). E sentenciava, na época: "a vida pública não vai bem e o jornalismo como profissão está em dificuldade", o que era uma forma de encorajar os jornalistas, demonstrando como um "novo propósito para reanimar uma profissão demolida e errante", além de assegurar aos cidadãos

\footnotetext{
${ }^{5}$ Algumas figuras do ideário da representação social dos jornalistas: "Cão de Guarda", "Artista e Intelectual", "a verdade acima de tudo", "o patrão é a sociedade", "o repórter é o herói da democracia", "informante fiel", "o bom jornalismo", "autofiscalização com o ombudsman", "o bom e velho jornalismo", "missionário: o direito de ser informado é a missão de informar" (OLIVEIRA, 2005)

${ }^{6}$ Em vista de não ter todo esse aparato de atributos, tanto o Jornalismo Investigativo quanto o Jornalismo Público, são tidos como gêneros. Um por ir além do Jornalismo Informativo apenas na questão da apuração investigativa. E o outro apenas por alterar a envergadura dos valores-notícia imputando uma abordagem com uma lógica não exclusivamente de consumo (tiragem, polêmica, chamar a atenção, denúncia, instituições democráticas), mas de cidadania também (diálogo, reinvindicação, utilidade pública, formação crítica, cidadão na democracia).
} 


\section{míDiA

preocupados com a viabilidade da vida pública, que essa mesma "vida pública também pode ser reanimada" (MERRIT apud TRAQUINA, 2003, p.173).

\section{A retomada do Sujeito: Jornalismo Público e Novo Jornalismo}

O Jornalismo Público, tomado como modelo alternativo e emergente de exercício da profissão, é uma investida mais sobre os valores-notícia do que todo o aparato criado pós-Objetividade, circunstanciado pelo Jornalismo Informativo. O intuito é de reformar os valores-notícia e ampliar a atuação do repórter (sujeito) não em função de um mercado (empresário de comunicação e público consumidor/leitor), mas em termos de cidadania (instituições e cidadão), principalmente no que evoca o direito de ser informado e o dever do Jornalismo (e das instituições) de informar ao cidadão: itens importantes da vida pública e do interesse público. Sendo que, o Jornalismo Público (sujeito a serviço da cidadania) não se confunde com o Novo Jornalismo (sujeito a serviço da narrativa), que resgata a questão do sujeito no discurso e textos jornalísticos, não no sentido tradicional da literatura, mas ainda dentro dos formatos noticiosos tradicionais, que configura mais um gênero jornalístico do que um modelo ${ }^{78}$.

Ainda nos EUA, um crítico do Jornalismo Público foi o teórico Michael Schudson, mas que reconheceu a força da revitalização filosófica ao declarar o movimento como "o mais bem organizado dentro do jornalismo, na história da imprensa americana" (SHUDSON apud HAAS, 2007, p. 17). O autor já pensava que os jornalistas não eram simples observadores passivos, mas participantes ativos no processo de construção da realidade. E também que as notícias não poderiam ser vistas

\footnotetext{
7 Aliás, depois de 20 anos, algumas pesquisas têm demonstrado que o Jornalismo Público tem se instalado no Brasil com força de gênero jornalístico e não como modelo de Jornalismo. Ele entra no noticiário, mas em alguns espaços e com alguns profissionais. Mas ele não se firmou como o discurso coletivo e substancial a ser chamado de modelo, no rigor da concepção.

${ }^{8}$ Há também a discussão quanto ao sujeito: o Jornalismo Público (cidadania) e o Novo Jornalismo (narrativa) estariam (ou não) resgatando o sujeito no Jornalismo. Um argumento diz que o sujeito está sendo incluído pela primeira vez dentro do jornalismo como profissão. Outros, dizem que a opinião e o sujeito nunca saíram do Jornalismo efetivamente (Jornalismo Interpretativo, Jornalismo Opinativo) e que as ideologias dominantes na profissão é que davam a sensação de que o sujeito tinha sido extirpado junto com o Jornalismo Literário.
} 


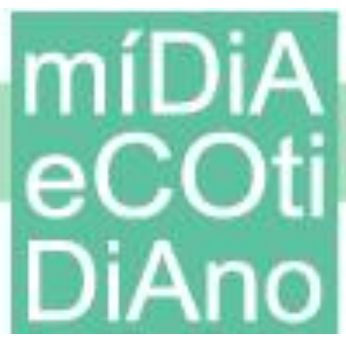

como emergentes naturalmente dos acontecimentos do mundo do real; as notícias acontecem na conjunção de acontecimentos e de textos. Enquanto "o acontecimento cria a notícia, a notícia também cria o acontecimento" (Traquina, 1988, p. 30). Também fazia uma divisão entre o cidadão informativo (saturado com bits e bites de informação) e o cidadão informado (que não apenas tem a informação, mas é capaz de construir um ponto de vista a partir de coisas que fazem sentido). (Schudson, 1995, p. 28).

A partir do conceito de cidadão informativo e cidadão informado o leitor pode até pensar que Schudson era entusiasta do Jornalismo Público. Não era. Mas a proposição de utilidade pública da informação, como o serviço e a educação, são perspectivas que emergem no cenário dos anos 1980 e 1990, em vias de neoliberalismo. A pesquisa em Comunicação já percebia isso.

As bases conceituais do Jornalismo Público estão em Davis Merritt, mas também em John Dewey (sobre a natureza do público), Walter Lippmann (relação entre jornalistas e público) ${ }^{9}$ e a ainda a Comissão Hutchins (liberdade de imprensa, Teoria da Responsabilidade Social $^{10}$ ), que dão base à ressignificação da função social do Jornalismo num modelo alternativo de exercício da profissão com a prescrição de um ethos para além da matriz liberal, iluminista e utilitarista. O Jornalismo Público já é encontrado em todos os continentes. Há iniciativas na África, (Malauí, Senegal e Suazilândia), na Ásia e Oceania (Japão, Austrália e Nova Zelândia), Europa (Dinamarca, Finlândia e Suécia) e na América Latina (México, Argentina e Colômbia).

\section{Jornalismo Público: contexto nacional}

Fernandes (2004 2008 2009) se dedica à questão histórica da importação do modelo de Jornalismo Público para o Brasil e sua configuração no contexto nacional. Já

\footnotetext{
${ }^{9}$ A gênese do Jornalismo Informativo se relaciona diretamente com Walter Lippmann. Uma curiosidade, ele foi congratulado duas vezes com o Prêmio Pulitzer por sua coluna: "Today and Tomorrow" (no ano de 1958 e de 1962).

${ }^{10}$ Embasamento nas teorias comunitárias da filosofia política, em trabalhos de James Carey, Hannah Arendt e Jürgen Habermas. Toda a carga de ethos, ética e eticidade, desse universo do Jornalismo Público, vem daí. Além da tentativa de redefinir a função social do Jornalismo rompendo com a herança liberal iluminista e utilitarista. É uma crítica ao liberalismo e tem uma característica um tanto normativa, com ênfase na justiça social e na democracia participativa.
} 


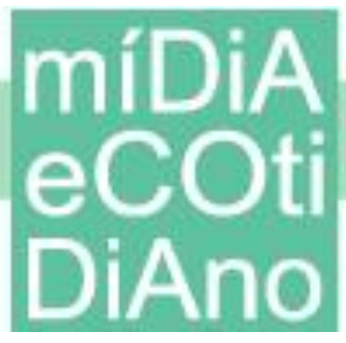

PPGMC

Silva (2002 2003 2004) entra num caráter mais conceitual relativo à Teoria da Notícia e implicações relativas principalmente aos valores-notícia e agendamento. Existem outros pesquisadores que trabalham em estudos de caso sobre aplicação do modelo no país, sendo que Moraes (2011) foi o que mais se dedicou a uma compilação bibliográfica sobre o tema. Para o autor, no Brasil, não se pode dizer que haja uma história do Jornalismo Público, muito menos uma tradição, a julgar pelo contexto norte-americano, principalmente no tocante a sua configuração como movimento (EUA) e como modelo (padrão). Pra o autor, é possível encontrar nos veículos comerciais algumas iniciativas pontuais de jornais que querem participar de forma mais ativa de suas comunidades ou se aproximar de seus públicos (gênero jornalístico), mas com pouca associação ao conceito de Jornalismo Público. Nas mídias públicas, em especial nas emissoras de TV, a discussão sobre Jornalismo Público é mais frutífera. Emissoras como a Rede Minas, TV Cultura e TV Brasil afirmam que seus noticiários realizam Jornalismo Público. É na academia, contudo, que o conceito transita com maior naturalidade.

É verdade que a noção de accountability, retomada no neoliberalismo (anos 1990 para cá), também ajudou no crescimento deste paradigma. A própria ideia da administração pública de Orçamento Participativo tem a ver com isso. Ou ainda os mecanismos de Ouvidoria, Serviço de Atendimento ao Cliente e Fale Conosco nas instituições do mercado. Assim como a emergência da autocrítica noticiosa (Ombudsman ${ }^{11}$, Espaço do Leitor) ou crítica de mídia (Observatórios de Imprensa). Já no âmbito da mídia, a noção de Comunicação Pública também ajudou a ampliar este contexto $^{12}$, pois desenvolveu a ideia de prestação de contas das instituições e aumentou o fluxo de informações.

Silva (2004, p. 8) estuda o Jornalismo Público com enfoque na Teoria da Notícia. E percebe que, veículos de comunicação dão ênfase a questões secundárias, em detrimento de prioritárias, do ponto de vista da cidadania. Este contexto tem a ver com

\footnotetext{
${ }^{11}$ M. Fernandes (2009, p. 124) considera o ombudsman um elemento do Jornalismo Público, mas que sozinho não se justifica nos jornais comerciais tradicionais por se tratar de "uma espécie de Daniel na cova dos leões".

${ }^{12} \mathrm{O}$ ombudsman, programas com ênfase no telespectador como Globo Comunidade e O Povo Fala, campanhas ou coberturas temáticas como Eu quero paz, Paz no Trânsito (do jornal Correio Braziliense) têm essa dimensão de cidadania.
} 


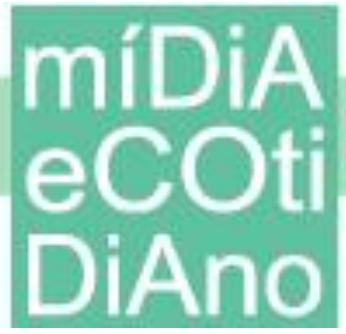

os valores-notícia subjugados à lógica do mercado, o que incorre na visão do Jornalismo Informativo de ver o público como leitor ou consumidor de produtos e serviços noticiosos, tão somente. Para o autor, o Jornalismo Público dá ênfase às soluções dos problemas e não aos problemas em si.

\section{O Sujeito e Cidadania}

O Jornalismo Público tem se apresentado como gênero jornalístico nas redações, mas tem se consolidado como modelo no Jornalismo Institucional. É de suma importante frisar isto, pois difere muito da realidade dos EUA e de outros países, pois, no Brasil, desde os anos 1980, aceita-se e compreende-se que os jornalistas também podem estar nas assessorias das organizações e produzir informação. A partir de exemplos citados por Silva (2004) podemos classificar a adaptação do Jornalismo Público como modelo no país, alocado nas organizações na perspectiva de Jornalismo Corporativo (jornalismo para jornalistas) a julgar pelo patrocínio da Agência de Notícias dos Direitos da Infância (Andi) com redação especializada sobre a pauta da criança e da adolescência.

Ainda nos exemplos citados por Silva (Idem), podemos classificar a adaptação do Jornalismo Público como gênero jornalístico no país, alocado nas organizações na perspectiva de Jornalismo Institucional a julgar pelas campanhas, em série de reportagens Paz no Trânsito e Sou da Paz ou selos em coberturas do Correio Braziliense.

Outro tipo de adaptação vislumbrado no contexto brasileiro é a partir do Jornalismo Institucional: em iniciativas organizacionais de promoção do bem-estar coletivo, tais como Empresa Voluntária (CBN), Globo Comunidade (Rede Globo). Ou ainda guias: Guia de Boa Cidadania Corporativa (1), Guia Exame das 100 Melhores Empresas Para Você Trabalhar (2) e Guia para Fazer o Bem (3). Além de suplementos como o Profissão Solidário, seminários e eventos como o Criança Esperança e Ação Global. Percebe-se que nesses casos o bônus das iniciativas não são voltados diretamente para a empresa, mas para a coletividade. Logicamente, promovem a 


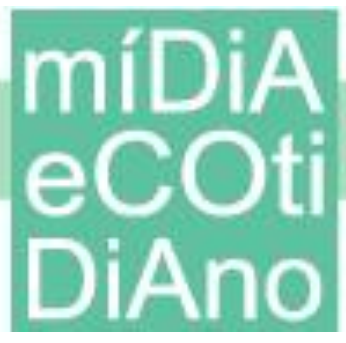

imagem institucional, mas não deixam de ser práticas de utilidade pública (e não apenas institucional).

A adaptação do Jornalismo Público na sua dimensão promocional, no tocante à ação de responsabilidade social da mídia, está centrada nos prêmios e todo o aparato de assistência aos jornalistas nas rotinas produtivas: oferecimento de ferramentas e suporte contínuo de pautas e informações à cobertura (publicações, estudos técnicos, boletins, balancetes, clipping, relatórios e metodologia para eventos de divulgação). Nos exemplos de Silva, iniciativas percebidas no trabalho de Instituto Ethos, Rede de Informações para o Terceiro Setor (Rits) e o Ibase.

Se no contexto internacional ${ }^{13}$, o Jornalismo Público se configurou como movimento. No contexto nacional, ele foi adaptado de forma fragmentada: encontrando espaço de atuação como modelo e como gênero jornalístico. Como modelo, ele está consolidado no Jornalismo Institucional, principalmente o praticado pelo Terceiro Setor, fato já verificado por diversos autores ${ }^{14}$.E, como gênero, em coberturas, selos e temas esporádicos nas redações. O curioso, no caso brasileiro, é como o Jornalismo Público se instalou tanto nas redações quanto nas assessorias. Nos EUA, onde está a origem do movimento, as assessorias são domínio dos profissionais de relações públicas. E não se considera o trabalho das organizações como informação jornalística;

\footnotetext{
${ }^{13}$ Citam-se ainda: OhMyNews OhMyNews (site coreano com versão internacional) (1), WikiNews (site baseado no modelo wiki) (2), AgoraVox (site francês) (3), Asturias Opinión (site espanhol) (4), CentPapiers (site canadense) (5), Giornalismo Partecipativo (site italiano) (6), GlobalVoices (comunidade de blogueiros voluntários) (7), iBelarus (site bielorruso) (8), Orato (site que valoriza relatos testemunhais em primeira pessoa) (9), Rue89 (site francês) (10), SOS Periodista (site argentino) (11), Spot.Us (site que arrecada fundos para coberturas cidadãs) (12), SwaBerita (site indonésio) (13), Flickr Citizen Photojournalism (canal de fotojornalismo cidadão) (14), YouTube CitizenNews (canal de videojornalismo cidadão) (15), NowPublic (site que mantém parceria com a agência de notícias AP) (16), CitizenSide (da agência de notícias AFP) (17), NewsVine (do conglomerado americano MSNBC) (18), CBS EyeMobile (do conglomerado americano CBS) (19), CNN iReport (do canal de tv CNN) (20) e ElPaís yoPeriodista (do jornal espanhol El País) (21). Fonte: Overmundo Lab.

${ }^{14}$ Paulino (2003), Vidal (2003), Barros (2003), Crispim (2003), Batista (2004), Lima (2005), Bonfim (2005), Rossy (2006), Magno (2006), Vargas (2006), Castro (2006), Barros (2007), Paulino (2008), Oliveira (2008), Mora (2008), Dias (2008), Borges (2008), Vidal (2009), Medeiros (2010), Gonçalves (2010), Pedreira (2010), Moraes, (2011).
} 


\section{míDiA

somente como promocional. A riqueza deste universo também está nessa nuance, que causa estranhamento e numerosas tensões, a serem investigadas pela ciência ${ }^{15}$.

\section{Relação entre prêmios e modelos jornalísticos}

O artigo trabalha com duas linhas majoritárias: relativas ao Jornalismo Informativo (objetividade), que fomenta a figura do jornalista cão de guarda (Democracia Representativa, quarto poder, isenção, denúncia); e Jornalismo Público (sujeito), quanto à questão do profissional socialmente responsável (Democracia Participativa, poder social, atuação e serviço).

No Brasil, o Prêmio Esso foi o grande fomentador dos modelos de Jornalismo Informativo (anulação do sujeito: isenção, impessoalidade e imparcialidade) e Jornalismo Investigativo (cão de guarda: denúncia). Entretanto, em quase 60 anos de existência, a premiação absorveu categorias que contemplam práticas recentes, a julgar por estudos, como: Cassol (1997), Magno (2006), Passos (2007), Castilho (2010) e Dias (2013). Um bom exemplo prêmio que pode ter categorias e subcategorias de premiação, vinculados a diferentes modelos jornalísticos, é estudado por Mora (2008) em dois prêmios com nomes parecidos: o Prêmio Tim Lopes de Investigação Jornalística (Rede Globo) e o Concurso Tim Lopes de Investigação Jornalística (ANDI). O primeiro trabalha com honrarias em relação a reportagens pós-veiculadas na mídia. E o segundo com a pré-produção de reportagens ainda em formato de pautas. O da Rede Globo é ligado diretamente a denúncias e o romper do Jornalismo Investigativo. O da ANDI é ligado à cidadania e ao serviço de discussão dos dilemas sociais, como o problema das crianças e adolescentes em situação de risco. Ambos trabalham com reportagem e investigação, mas a partir de valores diferentes: valores-notícia e valores-serviço. Pode parecer um pleonasmo, mas todo jornalismo é investigativo (1). Todo jornalismo é público (2). E todo jornalismo profissional é informativo (3). Entretanto, quando

\footnotetext{
${ }^{15}$ Citam-se ainda: Oficina Overmundo passeio por experiências de jornalismo cidadão (1), IG Eu na Web (do portal IG) (2), Terra vc Repórter (do portal Terra) (3), O Globo Eu-Repórter (do jornal carioca O Globo) (4), GazetaOnline Eu Aqui! (da Rede Gazeta de Vitória, ES) (5). Fonte: Overmundo Lab.
} 


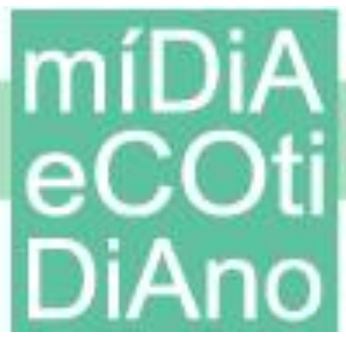

fechados em um modelo, a investigação (1), o interesse público (2) e a informação noticiosa (1), recebem marcações conceituais e taxativas que podem não corresponder à realidade, apesar de funcionarem bem como demarcação de um tipo de práxis. Veja: o Prêmio Esso é tido como baluarte no sentido das tipologias de Jornalismo Informativo e Jornalismo Investigativo. No entanto, ele tem criado categorias específicas que aglutinam práticas e valores do Jornalismo Público. No mesmo prêmio, existe o apoio e incentivo a um modelo de isenção e outro de atuação do jornalista. Os prêmios, por excelência, têm se mostrado híbridos em muitos casos.

O Prêmio Esso, ao longo de seus quase 60 anos, tem um viés menos enfático dos pilares do Jornalismo Informativo, no tocante à figura do repórter, do Jornalismo Investigativo e dos critérios de Objetividade. O nome Prêmio Esso de Reportagem (foco no gênero) incorporou categorias regionais, prêmios de Reportagem e Fotojornalismo, destaques especiais, votos de louvor, menções honrosas, além dos modelos de Jornalismo Esportivo, Jornalismo Econômico e Jornalismo Científico. Em 2010, tinha 13 categorias fixas, incluindo algumas específicas de imagem: Criação Gráfica e Primeira Página. Sem falar no complexo sistema de julgamento em duas instâncias, com quase 80 jurados compondo as comissões de avaliação e seleção (CASTILHO, 2010, p. 13). Não existe na literatura ou até em pesquisas específicas (CASSOL, 1997; SANTOS, 2004; MAGNO, 2006; PASSOS, 2007, GONÇALVES, 2010) a informação precisa sobre o ano exato da mudança do nome para Prêmio Esso de Jornalismo (foco global na atividade jornalística). Sabe-se que, suas categorias são: Principal (existente em todas as edições, exceto 1966), Reportagem (nas edições de 1966, 1967, 1968, 1971 e 1972), Regional ${ }^{16}$ (em todas as edições), Fotografia (em todas as edições), Reportagem Esportiva (em todas as edições, exceto 1967 e 1968, quando as matérias vencedoras na categoria principal abordaram essa temática), Informação Econômica (em todas as edições, exceto 1964 e 1965), Informação Científica (em todas as edições, exceto 1964 e 1965, sendo que a categoria passou a se chamar "Informação científica e tecnológica" em 1977 e 1978), Equipe (nas edições de 1964 a 1970; 1973 a 1975) e

\footnotetext{
${ }^{16}$ Regionais (Centro-Oeste, Norte e Nordeste (juntos), Sul e Sudeste.
} 


\section{míDiA

Melhor contribuição à imprensa (nas edições de 1971 a 1975) (CASTILHO, 2010, p. 315). Na edição 2010, com regulamento na amostra da presente tese, além da informação de Castilho (2010), percebe-se a expansão do viés em Jornalismo Científico na categoria Informação Científica, Tecnológica ou Ambiental com uma alternativa que poderia ser enquadrada em Jornalismo Público, dentro da questão temática desenvolvida sobre temas e 8 Objetivos do Milênio. Também surge a categoria Educação, além da Revista (ambas não citadas no levantamento de Castilho).

O Prêmio Esso, por si, só, já mostra que aquela perspectiva específica de Jornalismo Informativo (Objetividade: isenção, imparcialidade e impessoalidade) e Jornalismo Investigativo (reportagem, denúncia) não é mais o único ethos a ser premiado em Jornalismo. Os temas de educação e ambientalismo, típicos de uma abordagem do Terceiro Setor ou, de forma mais ampla: da Sociedade Civil, são temas incorporados recentemente. Ora, sabe-se que o tema da educação aparece muito em premiações, no caso da amostra: relativos a políticas públicas como do Plano Nacional de Educação (PNE): Prêmio $A M B^{17}$ e Prêmio $C N P G^{18}$. Também aparece de forma difusa em Prêmio Estácio (Educação).

O mesmo acontece com o ambientalismo ("meio ambiente", "sustentabilidade", "sustentabilidade ambiental"), tema vinculado ao caráter de responsabilidade socioambiental, tema comum em premiações do universo do Jornalismo Institucional, conforme negrito:

- $\quad$ Prêmio CNT (Meio Ambiente);

- $\quad$ Prêmio ALLIANZ Seguros (Meio Ambiente);

- $\quad$ Prêmio CBN de Jornalismo Universitário (Sustentabilidade);

- $\quad$ Prêmio Comunique-se (Sustentabilidade);

- $\quad$ Prêmio Itaú de Finanças Sustentáveis (Meio Ambiente);

- $\quad$ Prêmio Aberje (Sustentabilidade, Código de Defesa do Consumidor);

- $\quad$ Prêmio ANA (Meio Ambiente, Recursos Hídricos); e

\footnotetext{
${ }_{17}^{17}$ Associação dos Magistrados Brasileiros (AMB), entidade que reúne 14 mil juízes em todo o Brasil.

${ }^{18}$ Conselho Nacional dos Procuradores-Gerais (CNPG)
} 


\section{míDiA

- $\quad$ Prêmio Jovem Fernando Pacheco Jordão (8 Objetivos do Milênio, no tocante ao Objetivo 7: garantir a sustentabilidade ambiental)

O curioso no Prêmio Esso é o ambientalismo entrar como tema alternativo à questão tecnológica (Informação Científica, Tecnológica ou Ambiental) e não; como tema aditivo (Informação Científica, Tecnológica e Ambiental). Se pensarmos em termos de modelos, é como se o Jornalismo Público (responsabilidade ambiental) fosse fundido dentro do Jornalismo Científico (avanços tecnológicos e científicos).

Outro fato curioso é que no Prêmio Esso também notam-se valores subjetivos que vão contra a rigidez de outrora, postulada pelo modelo de Jornalismo Informativo (Objetividade: isenção, imparcialidade e impessoalidade). O edital 2010 expressamente tem como critério de avaliação dos trabalhos: "esforço acima do comum", "virtudes jornalísticas e pessoais" e "coragem, determinação, perseverança, senso de oportunidade e isenção"19 . Atualmente, os temas mais premiados são: Eletricidade e Segurança de Energia (2\%), Educação (25\%), Código de Defesa do Consumidor (15\%), Combate ao Crime Organizado (5\%), Saúde (5\%), Idosos (2\%), Infância e Adolescência (15\%), Portadores de Necessidades Especiais (10\%), Igualdade Racial (2\%), Recursos Hídricos (2\%), Cidadania (10\%), 8 Objetivos do Milênio ${ }^{20}$ (2\%), Bem Estar Social (5\%) (DIAS, 2013).

Objetos de premiação: o profissional e empresas como sujeitos

Inicialmente, como Prêmio Esso, nos anos 1950, as premiações eram feita tendo como objeto o trabalho jornalístico, com o intuito de fomentar o noticiário com um tema ou com um padrão de matéria jornalística referente aos moldes da adoção dos

\footnotetext{
19 “O Prêmio Esso de Reportagem [como categoria do Prêmio Esso de Jornalismo] será conferido, preferencialmente, ao trabalho em que ficar evidenciado esforço acima do comum por parte do repórter ou de equipe de jornalistas para obtenção das informações utilizadas na matéria. O Prêmio Esso De Reportagem tem como objetivo o reconhecimento público de virtudes jornalísticas e pessoais dos repórteres como coragem, determinação, perseverança, senso de oportunidade e isenção, entre outras, expressas no trabalho publicado", regulamento Prêmio Esso 2010.

${ }^{20}$ Termo guarda-chuva de editais da ONU para prêmios que tratem de Desenvolvimento nacional (Objetivo 1), Educação (Objetivo 2), Gênero (Objetivo 3), Saúde Infanto-Juvenil (Objetivo 4), Saúde materna (Objetivo 5), Saúde coletiva (Objetivo 6), Sustentabilidade (Objetivo 7) e Desenvolvimento internacional (Objetivo 8)
} 


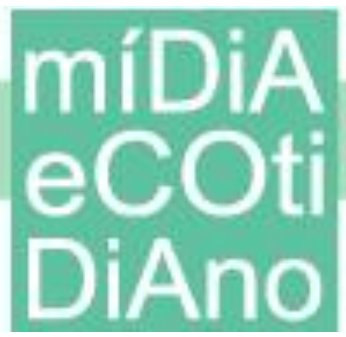

PPGMC

critérios de Objetividade e dos modelos de Jornalismo Informativo e Jornalismo Investigativo. Os critérios objetivos tiveram como efeito a separação entre informação e opinião (1), redações e assessorias (2), jornalismo e relações públicas (3). Os prêmios relativos aos modelos de Jornalismo Empresarial, Comunicação Empresarial, Jornalismo Corporativo e Jornalismo Institucional tinham como objeto de premiação o próprio profissional, uma característica herdada da lógica de Comunicação Empresarial de se premiar a pessoa e não só o fruto de se trabalho, como "prêmio personalidade do ano" etc.

A partir do neoliberalismo e da ascensão do Terceiro Setor, com a instrumentalização das ONG's com estratégias de comunicação com vistas à inserção e conteúdo no Espaço Público, percebe-se certa apropriação da lógica de Jornalismo Institucional. E, com isso, do crescimento do número de prêmios com objeto de premiação sendo o sujeito: seja ele o jornalista ou a empresa jornalística. Vale lembrar que este fenômeno é notado no Brasil a partir da concepção de que, no país, os jornalistas também trabalham em assessorias com a perspectiva de Jornalismo (Jornalismo Empresarial, Jornalismo Corporativo e Jornalismo Institucional) e não de Relações Públicas (Comunicação Empresaria e Comunicação Interna). Este clima de personalização das premiações em sujeitos físicos (jornalistas) e jurídicos (empresas), além dos objetos frutos de seu trabalho (matérias), se relaciona com a ascensão da responsabilidade social como estratégia das empresas, tidas não mais como Setor Privado, mas como Segundo Setor.

Atualmente, os índices de setores que mais premiam o Jornalismo são: 11\% para Primeiro Setor, 35\% para Segundo Setor e 54\% para Terceiro Setor (DIAS, 2013).

\section{Formas de adesão aos prêmios}

O Jornalismo Informativo tende a ter como pressuposto a anulação do sujeito (isenção, impessoalidade e imparcialidade). E tem o compromisso de divulgar a informação de forma referencial, tendo o discurso do Jornalismo como relato da realidade com status de verdade comprovada. Nessa perspectiva, geralmente, 


\section{míDiA

organizações do Segundo Setor utilizam prêmios em dinheiro, menções honrosas e premiação de mérito a partir do lançamento de concursos, em editais/regulamentos públicos. A marca principal deste processo é a candidatura, como tipologia de adesão. $\mathrm{O}$ jornalista profissional que preencha os critérios mínimos de inscrição e concorrência pode participar. Na maioria das premiações, não há cobrança de taxas. E, quando há, elas costumam ser de custo baixo, para cobrir despesas administrativas apenas. A análise neste tipo de processo costuma ser sobre o trabalho jornalístico: reportagens, infográficos, fotografia etc. Os trabalhos são submetidos a uma comissão julgadora, composta por membros dotados de competência técnica, notório saber e de ampla reputação no meio profissional.

O Jornalismo Público coloca o jornalista como cidadão socialmente responsável e atuante no meio social, a partir da visão de Democracia Participativa. Além de trabalhar critérios de noticiabilidade e valor-notícia, agregam novos valores à produção de fatos jornalísticos ao elencar o que alguns autores chamam de valorserviço. A marca principal deste processo é o monitoramento, como forma de adesão. A partir de critérios organizacionais, a instituição que promove o prêmio passa a monitorar o trabalho do jornalista (1), o perfil do profissional em si (2), além do perfil da empresa na qual ele trabalha (3). E costuma nomear práticas, dentre essas três categorias, que a instituição premiadora julgue condizentes com o mérito de sua missão institucional $\left(A d v o c a c y^{2 l}\right)$. Como não há candidatura, em alguns prêmios, é possível um jornalista preencher os critérios mínimos de concorrência e nem saber disso. Há casos de jornalistas que já foram premiados e sequer sabiam que estavam concorrendo a algo. A cobrança de taxas costuma não existir. E também não costuma ser divulgado: a composição da comissão julgadora (1) e se existe avaliação por pares dos trabalhos (jornalistas com notório saber técnico e reputação no meio profissional) (2). Também não costumam ter a publicação de edital ou regulamento com a discriminação do número de concorrentes, critérios de análise e coisas tais. Até porque, nesta modalidade, mais de uma pessoa pode ser premiada na mesma categoria.

\footnotetext{
${ }^{21}$ Este processo visa o engajamento do jornalista na Advocacy em alguma iniciativa organizacional, póspremiação.
} 


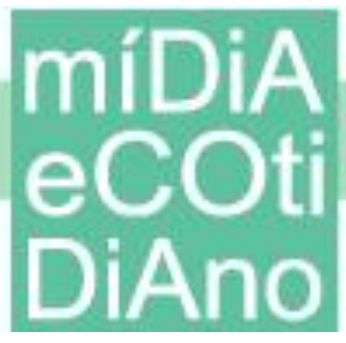

A adesão por candidatura costuma ter início com o lançamento de um edital ou regulamento (1), abertura do prazo de inscrições (2), envio de trabalhos (3), divulgação de resultados (4), período recursal (caso haja) (5), divulgação final dos vencedores e dos destaques (menções honrosas) e cerimônia para entrega dos prêmios. Nota-se que a execução do processo de certificação tem como ápice a entrega do prêmio, o que ocorre de forma diferente principalmente nos de adesão por monitoramento que utilizam a concessão de prêmio como uma convocação para adesão de um tema social (Advocacy $=$ defesa e promoção).

A adesão por monitoramento tem um viés tributário dos prêmios de marketing e RP, que trabalham mais com indicação e votações de um colégio de membros para nomear vencedores (podendo ser mediante inscrição ou não). Entretanto, nestas premiações da esfera organizacional e institucional, a entrega do prêmio é o fim do processo (e não, o início dele); com estratégias de doutrinação, capacitação e compartilhamento de ferramentas e experiências de trabalho.

Metaforicamente, se na adesão por candidatura o prêmio é quase um coroamento do "bom jornalismo", na adesão por monitoramento seria como um batismo institucional, com vistas ao engajamento de um membro.

\section{Conclusão}

Neste artigo, o objetivo foi o de abordar a retomada do sujeito em Jornalismo não apenas pelo prisma da notícia como elemento do processo de produção da notícia (Molotch e Lester), mas como sistema meritocrático dentro da cultura profissional (Schudson) e profissionalismo (Soloski). Não houve demonstração de todo o rol de prêmios que há sobre a questão do sujeito e a premiação dele, seja como jornalista ou empresa jornalística, listando " $n$ " prêmios em diversas categorias e ramificações de mérito. Entretanto, houve o cuidado de se apontar nichos nos quais se depositam a ideia de sujeito e de cidadania, evocadas pelo Jornalismo Público e, principalmente pelo Jornalismo Institucional, nas estratégias de premiação dos definidores primários (Hall et al) ou promotores da notícia (Molotch e Lester). Além da vinculação da crise de 


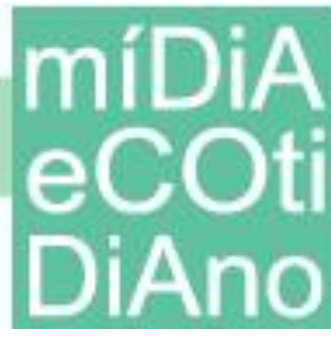

adoção dos critérios de Objetividade (anulação do sujeito) com a emergência exatamente da retomada deste sujeito, rechaçado por um modelo anteriormente.

Os prêmios tem tido certa atenção dos estudos em Comunicação, recentemente: Cassol (1997), Santos (2004), Magno (2006), Passos (2007), Carvalho (2007), Mora (2008), Dias (2008), Gonçalves (2010) Castilho (2010) e Dias (2013). E este tema tende a crescer na ciência. Ainda mais por mexer em temas pouco explorados. Por hora, propõem-se a circulação desse conhecimento na comunidade científica neste formato artigo em anais de congressos e periódicos.

\section{Referências Bibliográficas}

BORGES, Susana. A segunda fase do Jornalismo Público. Instituto Politécnico de Coimbra/Universidade Nova de Lisboa, Portugal. Estudos em Comunicação no5, 95113 Maio de 2009

CASSOL, Ivone. Prêmio Esso e as transformações da reportagem. (Dissertação, Mestrado em Comunicação), PUC/RS. 1997

CASTILHO, Marcio. Um patrimônio dos próprios jornais: as escolhas do campo jornalístico sob a ótica do Prêmio Esso. In: VII Encontro Nacional de História da Mídia, 2009, Fortaleza. VII Encontro Nacional de História da Mídia, 2009.

. A presença da Esso na imprensa brasileira. Rumores - Revista de Comunicação, Linguagem e Mídias. Vol. 2, No 1 (2008). Edição 3 - Julho-Dezembro de 2008

DIAS, Prêmios em Jornalismo: paradigmas em transição. (Tese, Doutorado em Comunicação), UnB. 2013

HACKETT, Robert. Declínio de um paradigma? a parcialidade e a objetividade nos media noticiosos. In TRAQUINA, Nelson (org.) Jornalismo: questões, teorias e estórias'. Lisboa, Vega, 1993, p. 101-132.

HALL, Stuart, CHRITCHER, Chas, JEFFERSON, Tony et alii. A produção social das notícias: o "mugging" nos media. In: TRAQUINA, Nelson. (Org.) Jornalismo: questões, teorias e estórias". Lisboa, Vega, 1993

MAGNO, Ana. A agonia da reportagem: das grandes aventuras da imprensa brasileira à crise do mais fascinante dos gêneros jornalísticos: uma análise das matérias 


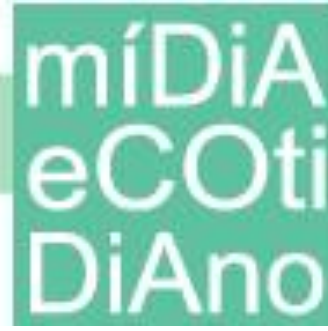

vencedoras do Prêmio Esso de Jornalismo. (Dissertação, Mestrado em Comunicação, UnB). 2006

OLIVEIRA, Daniel. Jornalismo para além do valor-notícia : o valorconvergente como modelo para selecionar e inserir temas sociais na mídia. (Dissertação, Mestrado em Comunicação), UnB. 2008

ROSEN, Jay. What Are Journalists For?, New Haven, London, Yale University Press, 1999.

SILVA, Luiz Martins (Org.); MATTOS, Heloiza; BRANDÃO, Elisabeth. Comunicação Pública. Brasília: Casa das Musas, 2003

Luiz Martins. Sociedade, esfera pública e agendamento. In: BENETTI, Márcia; LAGO, Cláudia. (Org.). Metodologia de pesquisa em jornalismo. 1 ed. Petrópolis: Vozes, 2007.

, Luiz. Jornalismo Público. o papel preventivo da imprensa. Observatório da Imprensa. Ano $17-n^{\circ}$ 731. Edição 687. Sexta-feira, 01 de Fevereiro de 2013. ISSN $1519-7670$

SOLOSKI, John. O jornalismo e o profissionalismo: alguns constrangimentos no trabalho jornalístico. In TRAQUINA, Nelson. Jornalismo: questões, teorias e estórias'. Lisboa, Vega, 1993.

TRAQUINA, Nelson (org). O estudo do jornalismo no século XX. São Leopoldo, RS: Ed. Unisinos, 2001.

1999.

, Nelson (org.). Jornalismo: questões, teorias, estórias. Lisboa, Vega, Nelson. A tribo jornalística: uma comunidade transnacional. Lisboa (Portugal): Editorial Notícias, 2004 . 